\title{
The Efficiency of Intravenous Theophylline on the Headache Which Occurs After Spinal Anesthesia
}

\author{
Hakan Akdere $^{\mathrm{a}, \mathrm{c}}$, Kamil Mehmet Burgazli ${ }^{\mathrm{b}}$
}

\begin{abstract}
Background: Headache which occurs after spinal anesthesia is the most frequent complication (30-40\%). In our study, we studied the efficiency of intravenous theophylline application on the patients who came with after spinal anesthesia headache (ASAH).
\end{abstract}

Methods: Sixty patients were included in this study. The patients were divided into three groups. The first group was given; intravenous (iv)200 $\mathrm{mg}$ theophylline $+1000 \mathrm{ml}$ Dextrose Linger lactate (DRL) with in half hour, the $2 \mathrm{nd}$, oral 100 mgcaffeine +500 $\mathrm{mg}$ paracetomol $+1000 \mathrm{ml} \mathrm{DRL}$ and the $3 \mathrm{rd}$, oral and iv placebo with $1000 \mathrm{ml}$ DRL within half hour. These patients were asked to degree the pain before the medicine was given and one hour after it was given using The Visual Pain Scala (VPS).

Results: In the first group, statistically significant difference was detected in the VPS results before and after the theophylline infusion $(\mathrm{P}<0.001)$. While the average VPS result was $(7.34 \pm$ $2.15)$ before, and $(2.2 \pm 2.04)$ after the infusion. In the second and third group, no statistically significant difference was detected in VPS $(\mathrm{P}>0.1)$.

Conclusions: The reason for the pain is the leak of the cerebrospinal fluid (CSF) from where the injection is given and the fall of CSF pressure. The agents like theophylline which causes vasoconstriction in brain veins help get over the headache. Our results tend to show that theophylline infusion after spinal anesthesia is a method which

Manuscript accepted for publication October 21, 2011

${ }^{a}$ Ozel Cerkezkoy Hastanesi, Tekirdag, Turkey

${ }^{b}$ Wuppertal Internal Medicine Clinic Germany, North Rhine-Westphalia, Germany

${ }^{\mathrm{c} C}$ orresponding author: Hakan Akdere. Email: hakdere@yahoo.com

doi:10.4021/jnr71e is efficient, fast and does minimal harm during the headache therapy.

Keywords: Lumbar puncture; Headache; Orthostatic headache; Spinal anesthesia complication

\section{Introduction}

Spinal anesthesia, one of the regional anesthesia techniques, is a frequently used method in lower extremity, hip, perineum, lower abdomen surgeries and caesarean deliveries [1]. Headache is the most frequently encountered complication after spinal anesthesia (30-40\%) [2]. The international Classification of Headache Disorders - 2nd edition describes ASAH under paragraph 7.2.1 [3]. 1/3 of them are severe, $1 / 3$ of them are moderate and the remaining $1 / 3$ are slight instances $[2,4]$. Usually, the headache starts within first one or two days, disappearing spontaneously or extending to two weeks [3]. The cause of the ache is the leak of spinal fluid (CSF) from the point of procedure and SF depression. The depression of CSF pressure results in the dilatation and contraction of blood vessels in tentorium and meninx [5].

The ache is felt more severe during standing up and sitting down, and diminishes while the patient is lying. It is felt more in the frontal area. The ache is accompanied by nausea and vomiting. The most important factor affecting the frequency of the headache is the thickness of the needle. The treatment consists of abundant hydration, oral analgesics, caffeine, theophylline, bed rest and stomach corset. As the last option, blood patch is used by injecting the patient's own blood $(10 \mathrm{~mL})$ taken in a sterile way via the epidural $[5,6]$.

The treatment of the headache occurring after spinal anesthesia through pharmacological medication is a minimally invasive treatment. Yet the oral treatment produces limited results. The parenteral pharmacotherapy is faster and more effective; and largely eliminates the necessity for more invasive procedures. In a study, the oral theophylline treatment $(282.7 \mathrm{mg})$ applied to 11 patients suffering from the post-puncture headache is compared with the placebo and it was observed that the theophylline was effective [7].

In our study we aimed at comparing the effectiveness 
of I.V. theophylline over the oral caffeine + analgesics and placebo for the headache occurring after spinal anesthesia.

\section{Materials and Methods}

Sixty patients were included in this study. Those patients consisted of persons operated by different clinics with spinal anesthesia. The ones whom were found to have hypertension, cardiac problems, hyperthyroidism and central neurotic system pathologies during the physical examination and the ones over the age of 60 were excluded. The included patients were informed according to the Declaration of Helsinki. Their signed consent was obtained for the operation.

The patients were divided into three groups. Each group consisted of 20 patients. The first group of patients was given $200 \mathrm{mg}$ teophylline $+1000 \mathrm{cc}$ DRL; the second, oral caffeine $(100 \mathrm{mg})+$ analgesic $(500 \mathrm{mg}$ paracetomol $)+1000$ cc DRL; and the third was given iv placebo and $1000 \mathrm{cc}$ DRL within half hour. The patients were asked for ache evaluation at sitting position 1 hour before and after they were given medication according to the visual pain scala (VPS). The medication requirements of all patients were again examined according to the VPS evaluations obtained at the second hour. While $75 \%$ of the patients belonging to the first group (15 patients) reported no requirement for further medication, the $25 \%$ of the patients in the second group (5 patients) reported no need for a second medication. However, only $5 \%$ of the patients belonging to the third group ( 1 person) reported no necessity for further medication. In the statistical analysis, SPSS V13.0, the VPS scores, both before and after the treatment, were measured via Wilcoxo comparison test. The VPS scores of all groups were compared with the scores of the control group by using Mann-Whitney U test. The $(\mathrm{P}<$ $0.05)$ value for age and gender of the included patients were calculated via the Chi-squared test.

\section{Results}

The first group consisted of 4 women (20\%) and 16 men $(80 \%)$ of $27-48$ age interval, the second group 4 women (20\%) and 16 men (80\%) of $27-59$ age interval, and the control group consisted of 4 women (20\%) and 16 men $(80 \%)$ of $23-52$ age interval. The average of age in the first group was $(37.9 \pm 13.11)$, in the second group $(39.4 \pm 14.06)$ and in the third group it was $(39.4 \pm 14.06)$. The differences between the groups in terms of average of age and gender were found statistically insignificant $(\mathrm{P}=0.68, \mathrm{P}=0.681, \mathrm{P}$ $=0.948)$. No complication was observed in the patients after the research. No statistically significant differences were found among the groups in terms pre-treatment VPS scores $(\mathrm{P}=0.29, \mathrm{P}=0.37, \mathrm{P}=0.55)$

In the first group, statistically significant differences to the highest degree were found in terms of VPS scores before and after the teophylline infusion $(\mathrm{P}<0.001)$. While the pre-infusion average VPS value was found to be $(7 \pm$ $2.15)$, the post-infusion average VPS value found as $(2.2$ $\pm 2.04)$. No statistically significant difference in terms of before and after the treatment of caffeine + analgesic was observed in the second group $(\mathrm{P}>0.05)$. The VPS value before the caffeine + analgesic treatment was found as $(7.3$ $\pm 3.15)$ and after the treatment it was found to be $(6.65 \pm$ $3.15)$. In the third group, the control group, there was no statistically significant difference in terms of VPS value before and after the placebo $(\mathrm{P}>0.05)$. Between the first and second groups' average VPS value after the treatment, there was statistically significant difference in favor of the first group $(\mathrm{P}<0.05)$. Statistically significant difference was also observed between the first and the third group's average VPS values $(\mathrm{P}<0.05)$. Nevertheless, no statistically significant difference was found between the second and third group in terms of their average VPS values $(\mathrm{P}>0.05)$. Only $5(25 \%)$ of the patients belonging to the first group required a second dose teophylline treatment. The second VPS scores of those patients presented significant decrease. 15 (75\%) of the patients did not require a second teophylline infusion.

\section{Discussion}

The cause for the orthostatic headache occurring after spinal anesthesia is the leak of spinal fluid and depression of SF pressure. The depression of SF leads to the dilatation and contraction of blood vessels in tentorium and meninxes. The ache starts within the first two days. It may diminish within several days or extend to two weeks. The theory of dilatation of intra-brain veins is accepted due to the success of vasoconstrictor agents such as caffeine and teophylline in the elimination of headache [8-10]. Teophylline realizes vasoconstriction through its inhibition effect over the adenosine receptors $[1,2,8]$.

Many methods have been used for the treatment of intracranial hypotension. Those include bed rest, hydration, caffeine, teophylline, stomach corset, epidural blood patch and epidural fluid infusion. The most effective treatment is the epidural blood patch, the success rate of which is $80-97 \%$ $[1,2]$. Various complications such as back ache or infection might be observed in this invasive method.

The treatment of the headache occurring after the spinal anesthesia with medication is a less invasive method when compared to the blood patch technique.

Another research conducted over 11 patients suffering from the headache occurring after spinal anesthesia compared the oral teophylline treatment with placebo and it was observed that teophylline was effective $[7,8]$. Another research in the literature reports that a 58-yearold patient, who had suffered from chronic headache, 
vomiting and nausea as she stood up, positively responded to the teophylline treatment [11]. In our study, the headache problem of the patients whom were treated with teophylline has diminished dramatically $(\mathrm{P}<0.001)$. The pace of response to ache was found to be quite fast. The fact that the response to treatment in the group which received caffeine + analgesic was statistically insignificant might be related to the use of single dose.

Our findings suggest that the use of teophylline infusion is effective and quick in the treatment of headache occurring after spinal anesthesia. Along with that, this treatment is preferable for being an easy, fast and minimally invasive. We suggest that the study of teophylline infusion effectiveness in larger groups together with longer ache controls might produce more precise results. In conclusion, we think that the compliance of our study with other similar studies, and inclusion of the treatment of caffeine in a larger group of patients in the study for the first time and comparing it with a control group are important details.

\section{References}

1. Chau-in W, Hintong T, Rodanant O, Lekprasert V, Punjasawadwong Y, Charuluxananan S, Tanudsintum S. Anesthesia-related complications of caesarean delivery in Thailand: 16,697 cases from the Thai Anaesthesia Incidents Study. J Med Assoc Thai. 2010;93(11):1274-1283.

2. Ergun U, Say B, Ozer G, Tunc T, Sen M, Tufekcioglu $\mathrm{S}$, Akin $\mathrm{U}$, et al. Intravenous theophylline decreases post-dural puncture headaches. J Clin Neurosci. 2008;15(10):1102-1104.

3. Headache Classification Subcommittee of the International Headache Society. The International
Classification of Headache Disorders. 2nd edn. 2004;24(suppl.1):1-160.

4. Schwarz U, Schwan C, Strumpf M, Witscher K, Zenz M. Postdural puncture headache: diagnosis, prevention and therapy. Schmerz. 1999;13(5):332-340.

5. Mokri B. Headache associated with abnormalities in intracranial structure or function: Low cerebrospinal fluid pressure headache. In: Silberstein SD, Lipton RB, Dalessio DJ, editors. Wolff's Headache and Other Head Pain. New York: Oxford University Press; 2001. p. 417 8,430-31.

6. Choi A, Laurito CE, Cunningham FE. Pharmacologic management of postdural puncture headache. Ann Pharmacother. 1996;30(7-8):831-839.

7. Feuerstein TJ, Zeides A. Theophylline relieves headache following lumbar puncture. Placebo-controlled, doubleblind pilot study. Klin Wochenschr. 1986;64(5):216218.

8. Straube A, Neudert C, Glas M, Bruning R, Padovan CS. The so-called spontaneous low CSF pressure pressure syndrome. Case results indicating a disturbance in CSF/ blood volume regulation. Nervenarzt. 2004;75(12):11941199.

9. Mokri B. Headaches caused by decreased intracranial pressure: diagnosis and management. Curr Opin Neurol. 2003;16(3):319-326.

10. Forderreuther S, Yousry I, Empl M, Straube A. Dilated cervical epidural veins and extra arachnoid fluid collection in orthostatic headaches. Neurology. 2001;57(3):527-529.

11. Hungs M, Schoen SW, Topper R, Noth J. Spontaneous intracranial hypotension: a rare cause of chronic headache. Fortschr Neurol Psychiatr. 1999;67(9):387390. 